\title{
The Right Angle: Visual Portrayal of Products Affects Observers' Impressions of Owners
}

\author{
Jonathon P. Schuldt \\ Cornell University
}

\author{
Sara H. Konrath and Norbert Schwarz \\ University of Michigan
}

\begin{abstract}
Consumer products have long been known to influence observers' impressions of product owners. The angle at which products are visually portrayed in advertisements, however, may be an overlooked factor in these effects. We hypothesize and find that portrayals of the same product from different viewpoints can prime different associations that color impressions of product and owner in parallel ways. In Study 1, automobiles were rated higher on status- and power-related traits (e.g., dominant, powerful) when portrayed head-on versus in side profile, an effect found for sport utility vehicles (SUVs) - a category with a reputation for dominance-but not sedans. In Study 2 , these portrayal-based associations influenced the impressions formed about the product's owner: a target person was rated higher on status- and power-related traits when his SUV was portrayed head-on versus in side profile. These results suggest that the influence of visual portrayal extends beyond general evaluations of products to affect more specific impressions of products and owners alike, and highlight that primed traits are likely to influence impressions when compatible with other knowledge about the target. (C) 2012 Wiley Periodicals, Inc.
\end{abstract}

Imagine that a love-struck friend is excitedly telling you all about a new boyfriend and happens to show you a picture of his automobile, a gleaming sport utility vehicle (SUV). The SUV is portrayed head-on, its headlights pointed directly toward you. As you attempt to integrate the varied information into a coherent impression of this new beau, it seems unlikely that you would pause to consider how your nascent impression might differ had his SUV been portrayed otherwise (say, in side profile). After all, why should it? No matter the angle at which the SUV is portrayed, the majority of the information you know about its owner, including his SUV, would remain unchanged.

This article argues that, to the contrary, the ways in which products are visually portrayed may indeed affect observers' impressions of owners. The article begins by reviewing empirical evidence that products themselves can influence impressions formed about their presumed owners. Whereas this work typically emphasizes the role of general, context-independent knowledge about products and brands, an alternative social cognitive framework that we advance emphasizes the role of relatively temporary, context-dependent representations. In light of growing interest in the role of visual design in consumer psychology (Hoegg \& Alba, 2008; Wedel \& Pieters, 2007), this article suggests that different visual portrayals of the same product, from the same brand, can activate different trait concepts that influence impressions of product and owner in parallel ways. Two studies find support for this prediction: Study 1 examines whether head-on and side profile portrayals of the same automobiles result in different impressions of those products, and Study 2 tests for parallel effects on observers' impressions of an automobile owner.

\section{PRODUCTS AND THEIR OWNERS}

As consumer researchers are well aware, products can influence observers' impressions of product owners, and consumers' choice of products often reflects considerations of identity expression and impression management (for discussions, see Belk, 1978, 1988; Kleine, Kleine, \& Kernan, 1993; Oyserman, 2009; Schembri, Merrilees, \& Kristiansen, 2010)—moreover, marketers draw on these considerations in their branding efforts (Allen, Fournier, \& Miller, 2008). A tacit assumption 
in much of this work is that products and brands come with associated trait concepts and related knowledge, and that these associations themselves are relatively stable and context independent (Aaker, 1997; Allen, Fournier, \& Miller, 2008; Fennis \& Pruyn, 2007). Recent research in social and cognitive psychology, on the other hand, emphasizes the constructive and contextsensitive nature of knowledge representations (e.g., Schwarz, 2007; Smith \& Semin, 2004; Wyer, 2008; Yeh $\&$ Barsalou, 2006); it highlights that even the representations of common objects, like chairs, vary markedly by context (Yeh \& Barsalou, 2006). In this vein, we suggest that the same product from the same brand may prime distinct meanings and trait concepts depending on its visual portrayal, a variable that has been largely neglected in social, cognitive, and marketing research. Drawing on findings from social psychology and consumer research, we predict that even seemingly mundane choices about visual portrayal, such as the angle at which to depict products, can foster different impressions of products and their owners alike.

\section{VISUAL PORTRAYAL AND PRODUCT IMPRESSIONS}

Marketers routinely make decisions regarding how to portray products in visual advertisements, and yet, relatively little research has examined the effects of visual portrayal on product impressions. Suggestive findings come from research on the effects of verticality on judgment. For example, research finds that people are judged as more powerful when they are depicted higher in visual-spatial displays (Giessner \& Schubert, 2007; Meier \& Dionne, 2009; Schubert, 2005), and that products are evaluated more favorably when viewed from upward-looking or eye-level camera angles relative to downward-looking angles (Meyers-Levy \& Peracchio, 1992). These effects are thought to reflect a learned association between height and superiority that functions as a heuristic, guiding impressions of people and objects. These and related findings (e.g., Peracchio \& Meyers-Levy, 1994, 2005) suggest that concepts associated with the way a product or brand is visually portrayed-not simply concepts associated with a product or brand itself - can markedly affect impressions of products. Visual portrayal may matter most for products that reveal different features when viewed from different angles (cf. Kraft, 1987), features that may underlie the activation of different trait concepts, which in turn may differentially affect impressions.

Multiple lines of research suggest that the automobile is one such product. Research into anthropomorphic aspects of product perception demonstrates that consumers readily perceive faces in the fronts of automobiles, including specific facial structures such as "eyes" (e.g., headlights: Aggarwal \& McGill, 2007; Ichikawa, Kanazawa, \& Yamaguchi, 2011; Landwehr, McGill, \& Herrmann, 2011; Windhager et al., 2008).
Moreover, humans show a tendency to think about products and people in parallel ways (Chandler \& Schwarz, 2010), and research has long found associations between direct eye gaze and high status and power in human social interactions (cf. Chiao et al., 2008; Dovidio, Ellyson, Keating, Heltman, \& Brown, 1988; Kleinke, 1986; Mignault \& Chaudhuri, 2003). Building on these findings, if people readily perceive faces and direct eye gaze in the fronts of automobiles, then head-on portrayals of automobiles may facilitate impressions of high status and power for the automobile itself. Furthermore, since traits associated with products have been shown to color observers' impressions of owners (Fennis \& Pruyn, 2007), these temporary, portrayal-based impressions may extend to the automobile's owner as well. If so, impressions of products and their owners are not merely a function of traits associated with a product per se but crucially depend on the product's visual portrayal, a point that-beyond its clear practical implications for marketers and visual communication-would carry theoretical implications for the prevailing view that the meaning of products and brands is relatively context independent and robust to such subtle manipulations.

\section{TRAIT APPLICABILITY}

Although social cognition research suggests that subtle changes to the way that products are visually portrayed may activate distinct trait concepts capable of influencing impressions, it further suggests that the extent of their influence depends on their applicability to the target. For instance, when participants were unobtrusively primed with trait concepts before forming an impression of a person planning to sail across the Atlantic, traits that were highly compatible with this knowledge (e.g., "adventurous," "reckless") affected impressions more so than did valence-matched traits that were less compatible (e.g., "kind," "hostile": Higgins, Rholes, \& Jones, 1977; for reviews, see Higgins, 1996; Wyer, 2008). Hence, it is unlikely that status and power concepts primed by head-on portrayals will affect impressions of all automobiles equally. Instead, their influence may be larger for automobiles with a preexisting reputation for dominance, such as SUVs (Vanderheiden, 2006), compared to automobiles without this reputation, such as sedans.

\section{THE PRESENT WORK}

Building upon recent work showing that traits associated with products can influence impressions of their owners (Fennis \& Pruyn, 2007), the present studies examine whether different visual portrayals (i.e., varying angles) of the same product (i.e., an automobile) will differentially affect the impressions formed about its owner (Study 2). To set the stage, we first consider whether these different visual portrayals can affect 
impressions of the automobile itself (Study 1). Because these effects should be most pronounced when traits are highly applicable to the target, Study 1 examines the effect of visual portrayal on impressions of SUVs versus sedans. Given that SUVs have been stereotyped as dominant, unnecessarily large, and even aggressive (Vanderheiden, 2006), head-on portrayals are expected to heighten status- and power-related impressions of SUVs in particular. Study 2 then examines the influence of visual portrayal on status- and powerrelated impressions of an automobile owner. Holding the product constant, the owner is expected to receive higher status/power ratings when his SUV is portrayed head-on.

\section{STUDY 1}

\section{Method}

Participants. A total of $N=492$ participants were recruited for a study about "impressions of vehicles" using advertisements posted on the community Web site Craigslist.org in various U.S. cities. Two separate but similar experiments were conducted. One hundred and thirty-seven people participated in an earlier experiment (August-September, 2007) and 355 participated in a later experiment (March, 2008). The experiments used different automobile stimuli (see below) and were largely similar except for some slight differences in wording and measures (e.g., different filler items). Analyses were conducted on the combined sample, offering increased statistical power and the inclusion of more automobile stimuli. Mean age of participants was approximately 37 years $(\mathrm{SD}=13$ years); over $80 \%$ reported having some college education and nearly half (49\%) held a bachelors degree; women outnumbered men two to one, and nearly $80 \%$ reported Caucasian/European ancestry.

Automobile Images. Eight different automobiles, four sedans and four SUVs, were randomly selected from lists of the top 10 most researched models in their categories on the Kelley Blue Book Web site (www.kbb.com) during the year of the study.

Portrayal angle (head-on vs. side profile) and automobile type (SUV vs. sedan) were between-subjects factors in the experimental design. Participants in the earlier experiment viewed the Honda Pilot (SUV) or Honda Accord (sedan); those in the later experiment viewed the Chevy Tahoe, GMC Acadia, or Jeep Wrangler (SUVs), or the Acura TL, Toyota Corolla, or Toyota Camry (sedans). Kelley Blue Book's $360^{\circ}$ viewing tool was used to generate head-on and side profile images of each automobile (see Figure 1 for example images). ${ }^{1}$

1 For purposes of ecological validity, automobiles were presented in their original color (ranging from white, to gray, to burgundy).
Procedure. Participants consented, provided some personal background information, and then rated their randomly assigned automobile on various 7point semantic differential scales. Four semantic pairs represented traits related to status and power (namely, submissive-dominant, weak-strong, powerless-powerful, and feminine-masculine); these ratings were averaged to form a composite variable, "status/power" ( $\alpha=0.85$ ). Remaining semantic pairs were related to general favorability ratings of the automobile (namely, undesirable-desirable, not stylishstylish, and not sexy-sexy) and were averaged to form a composite variable, "favorability" $(\alpha=0.80)$. Whereas we expected visual portrayal of these products to uniquely influence status/power impressions because the fronts of automobiles contain dominance-related visual characteristics (e.g., "eyes") absent in side views, no effect on favorability was expected. The semantic differential scales were presented on a single page in a randomized order, with the automobile image appearing directly to the left of each rating scale to maintain image visibility throughout the ratings task. Finally, participants completed filler questions about their driving habits and were debriefed. The questionnaire typically took less than five minutes to complete.

\section{RESULTS}

Collapsing across automobile models, the main analysis took the form of a 2 (portrayal angle: head-on vs. side profile) $\times 2$ (automobile type: SUV vs. sedan) betweensubjects ANOVA. Given gender's association with status and power in society (Eagly, Wood, \& Diekman, 2000), we tested whether gender significantly moderated any effect of portrayal angle on ratings. No such effect emerged and gender was dropped from the analysis $(F \mathrm{~s}<1, n s)$.

\section{Status- and Power-Related Trait Ratings}

Consistent with the main prediction, automobiles were rated significantly higher on status/power traits when depicted head-on $(M=4.23, \mathrm{SD}=1.17)$ compared to in side profile $(M=4.00, \mathrm{SD}=1.19), F(1,473)=6.02$, $p=0.02$. In addition, SUVs were rated more highly than sedans on status/power traits overall $(M=4.45$, $\mathrm{SD}=1.14$ vs. $M=3.74, \mathrm{SD}=1.11 ; F(1,473)=49.81$, $p<0.001$ ), consistent with the SUV's reputation for dominance. Importantly, these main effects were qualified by a significant interaction between portrayal angle and automobile type $(F(1,473)=5.35, p=0.02)$ : whereas head-on portrayals increased the status/power ratings of SUVs $(M=4.71, \mathrm{SD}=1.08$ vs. $M=4.22$, $\mathrm{SD}=1.15 ; F(1,249)=11.91, p<0.01)$, they did not influence the ratings of sedans $(M=3.75, \mathrm{SD}=1.05$ vs. $M=3.73, \mathrm{SD}=1.17 ; F<1, n s$; Figure 2 ). Followup analyses examining whether the effect of portrayal angle varied by specific SUV model found no evidence 

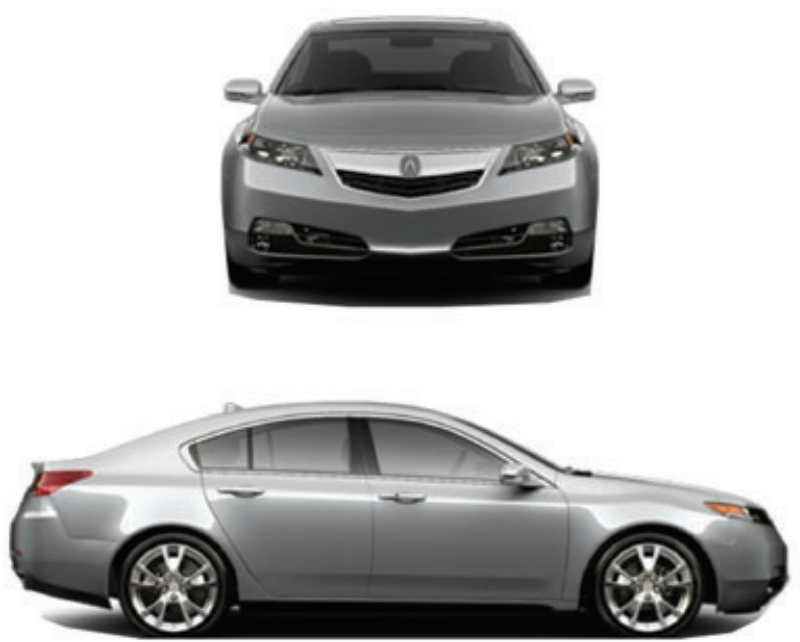
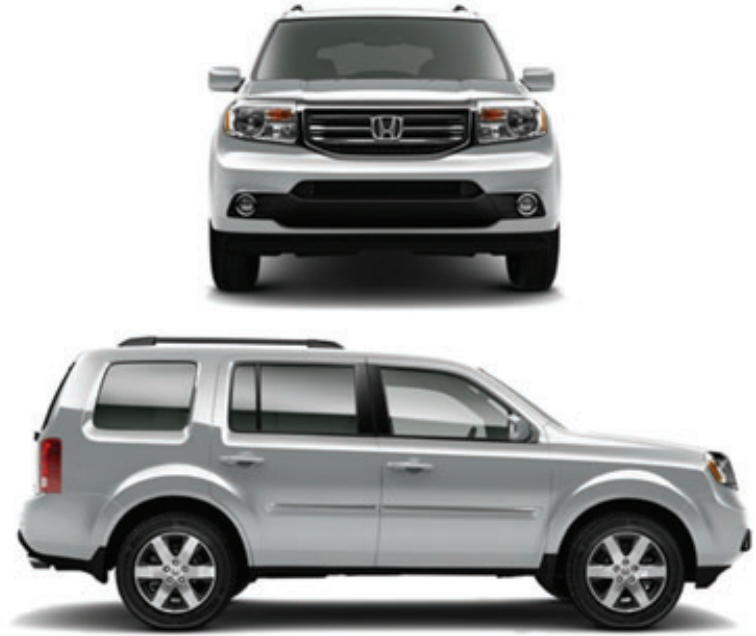

Figure 1. Example stimuli similar to those used in Study 1: a sedan (Acura TL) and an SUV (Honda Pilot), portrayed at different visual angles (head-on vs. side profile). Images reprinted with permission from the American Honda Motor Company.

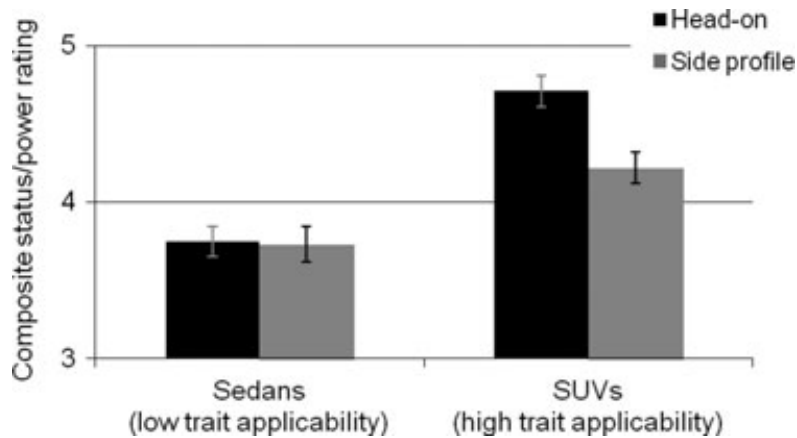

Figure 2. Graph displaying mean status/power ratings of the product as a function of portrayal angle and product type in Study 1. Error bars represent standard errors of the means.

for this (interaction $F<1, n s$ ). Finally and as expected, no effects of visual portrayal on favorability emerged $(F \mathrm{~s}<1, n s)$.

\section{DISCUSSION}

The finding that head-on portrayals of automobiles garnered higher status/power impressions extends the literature on visual marketing in several ways. First, it identifies a basic element of visual communication that can affect product impressions but has previously received little attention, namely head-on versus side profile portrayal angles. Compared to more unusual visual perspectives, such as steep camera angles (e.g., MeyersLevy \& Peracchio, 1992), viewers may be less likely to notice and correct for the influence of this variable when forming a judgment (Wilson \& Brekke, 1994). Second, whereas consumer research into visual product presentations has typically assessed general evaluations, such as aesthetic appeal and product favorability (cf. Hoegg \& Alba, 2008; Reber, Schwarz, \& Winkielman, 2004), these results suggest that visual portrayal can foster more specific product impressions as well, here related to status and power. Third, the choice of a head-on versus side portrayal angle had a stronger influence on impressions of SUVs. That is, angle only affected status and power ratings under conditions where these activated trait concepts were compatible with consumers' preexisting associations with the product (Vanderheiden, 2006). This echoes findings from numerous impression formation studies, in that concepts activated by the visual portrayals of products exerted their greatest effect when easily applicable and compatible with other knowledge about the target (Higgins, 1996; Wyer, 2008).

In light of these findings, Study 2 examined whether the differential associations evoked by head-on versus side profile portrayals of automobiles also colored impressions about automobile owners. Building on prior work suggesting that traits associated with products can influence impressions formed about owners (Fennis \& Pruyn, 2007), our Study 1 findings suggest that how the product is portrayed-not just the product itselfmay matter for these impressions, given that the same product (an SUV) evoked different impressions as a function of its visual portrayal. In short, might an SUV owner be perceived differently depending on a variable as mundane as whether his SUV is facing forward or to the side?

\section{STUDY 2}

To examine whether different visual portrayals of products can affect impressions of owners, participants completed a laboratory experiment in which they read a brief description of a target person (Adam), viewed a couple of pictures from his daily life which included a picture of his SUV, and reported their impressions of 
him. Only the SUV's portrayal angle was manipulated. Given that head-on SUVs activated status and power concepts in Study 1 and that primed trait concepts can affect impression formation in person perception (e.g., Higgins, Rholes, \& Jones 1977; Srull \& Wyer, 1979), we expected participants to rate the target higher on status- and power-related traits when his SUV was portrayed head-on.

Participants. One hundred and six students from the introductory psychology subject pool at a large Midwestern university participated in this lab experiment in exchange for partial course credit; 64 were female, 32 were male, and 10 did not report their gender.

Procedure. Participants were told they would complete a series of unrelated tasks, including one on impression formation. Participants consented, provided some background information, and then read the following bio-sketch:

\begin{abstract}
Adam grew up in Wilmington, Delaware, and he graduated from the University of Arizona with a business degree in 2004. While he was still an undergraduate, Adam was recruited by a mid-sized computer software firm based in Chicago, where he has worked ever since. Adam typically works full-time (approximately 45 hours) during the week (Monday to Friday), and he occasionally works on the weekends when necessary. In his free time, Adam enjoys watching Alfred Hitchcock movies, cooking, and hiking. During the winter season, Adam spends his vacation time skiing in the western states of Colorado and Wyoming.
\end{abstract}

Automobile Images. Beneath this description were two black-and-white "snapshots from Adam's everyday life." One photo showed his apartment building. The other photo showed his automobile, an SUV (namely, the 2007 Ford Expedition), which served as the critical manipulation: participants were randomly assigned to view either a head-on or side profile (facing right) image of the automobile. The descriptions were identical in every other respect. The SUV image was presented last, directly above the rating scales, to maintain image visibility throughout the ratings task.

Trait Ratings. Participants rated their impressions of Adam on 7 -point scales ( $1=$ not at all; $7=$ very much) featuring six status- and power-related traits. Three traits were carried over from Study 1 (dominant, powerful, and masculine); the others (hardworking, professional, and serious) were included to capture additional status/power traits relevant to the (businessprofessional) context conveyed in the bio-sketch. We predicted that Adam would be perceived as higher status/power when his SUV was portrayed head-on.

\section{RESULTS}

As in Study 1, gender did not moderate any effect of portrayal angle on impressions and was dropped from the analysis $(F \mathrm{~s}<1, n s)$.

The main analysis took the form of a one-way ANOVA testing for the effect of visual portrayal (headon vs. side profile) on the six status- and power-related ratings, which we averaged to create a composite variable, "status/power" ( $\alpha=0.73)$. Consistent with our hypothesis, Adam received higher status/power ratings when his SUV was depicted head-on $(M=5.30$; SD $=0.63)$ rather than in side profile $(M=5.03$; $\mathrm{SD}=$ $0.63) ; F(1,104)=4.74, p=0.03$, for the main effect of portrayal angle. Thus, head-on portrayals heightened perceptions of status and power for both the product (Study 1) and its owner (Study 2).

\section{DISCUSSION}

The present findings extend work showing that traits associated with different products can affect observers' impressions of their owners (e.g., Fennis \& Pruyn, 2007) by demonstrating that traits associated with different portrayals of the same product matter as well. Holding all other information constant, the owner of an SUV was rated higher on status- and power-related traits when his SUV was portrayed head-on versus in side profile. Thus, the prevailing view that products and brands carry relatively stable associated traits appears to be oversimplified; instead, the meaning of products may shift with subtle context manipulations, such as portrayal angle in visual communications, resulting in different impressions formed about product owners.

\section{GENERAL DISCUSSION AND CONCLUSION}

Together, results from these two experiments contribute to the literatures on visual representation in consumer judgment, product anthropomorphism, and person perception by demonstrating that merely portraying one side of a product versus another can facilitate different impressions of products and owners alike. In Study 1, SUVs were rated higher on a composite measure of traits related to status and power when those SUVs were portrayed head-on versus in side profile. This observation is consistent with the tendency to see faces in the fronts of automobiles (Windhager et al., 2008) and the relationship between direct eye gaze and dominance in human interactions (cf. Kleinke, 1986). That the effect was only observed for SUVs and not sedans is compatible with the general observation that primed concepts exert more influence when they are readily compatible with existing information about the target (Higgins, 1996; Wyer, 2008), facilitated by SUVs' widely-held reputation for dominance (Vanderheiden, 
2006). In Study 2, the influence of portrayal angle extended to the owner of an SUV, who was rated higher on status- and power-related traits when his SUV was portrayed head-on. These findings suggest that the associations brought to mind by products and brands are highly sensitive to subtle and mundane context manipulations and influenced by variables that themselves may appear to be "content free," such as the angle at which a product is portrayed in visual media. Such effects may seem surprising from the standpoint of rational information processing models given that the product itself, the target person, and the social context in which it was presented remained constant across conditions; however, such effects can often be predicted on the basis of metaphors (e.g., "staring you down") grounded in the social world (cf. Barsalou, 2008).

Whereas prior work in visual marketing has typically examined general evaluations, the present findings highlight that very basic visual marketing decisions can carry consequences for specific impressions as well. As marketplaces become increasingly transacted in complex online environments, illuminating the role of visual marketing cues in the consumer experience is increasingly critical (e.g., Darley, 2010); and for companies seeking to foster more specific impressions in order to remain competitive, we suggest that greater attention to trait-context congruence may allow for more nuanced predictions regarding the influence of visual portrayal on product impressions. For instance, as previously discussed, verticality is thought to cue superiority, with research finding that upward-looking visual angles increase ratings of favorability (MeyersLevy \& Peracchio, 1992). An emphasis on trait-context consistency suggests that these effects should be more pronounced for traits closely associated with the verticality metaphor (e.g., powerful) and among products to which those traits are easily applied (e.g., high-status goods). Future research may fruitfully address such predictions.

In the present work, we focused on the product category of automobiles because of the category's prominence and because different portrayal angles of automobiles were expected to differentially activate the status/power traits examined here. However, these findings are likely relevant to other product categories as well. Given that people readily see faces where they do not exist (Epley, Waytz, \& Cacioppo, 2007), any number of products in the marketplace with vaguely face-like features-from houses to wristwatches and smartphones-may be judged differently depending on portrayal angle. Yet importantly, as our findings suggest, it is unlikely that all products will be perceived as having higher status/power when portrayed head-on. Just as direct eye gaze may prime dominance when it comes from a military commander but not an infant, consumers' preexisting knowledge about products is likely to matter. For example, head-on depictions may increase status/power impressions of exclusive luxury watches (e.g., a $\$ 28,000$ Patek Philippe) but not of their less-expensive counterparts (e.g., a \$28 Timex).
There are some limitations to the present work. Participants were not representative of the consumer public, given that both samples were predominantly white, female, and college educated. In addition, these data do not speak to the presumed mediating process for these effects, that is, the perception of metaphorical eye gaze in the fronts of automobiles. Although the present effects on status and power impressions converge with previous findings to suggest metaphorical eye gaze as a likely mediator (cf. Kleinke, 1986; Windhager et al., 2008), future research employing direct measures of the mediating process (e.g., Ichikawa, Kanazawa, \& Yamaguchi, 2011) or diagnostic situational manipulations (e.g., anthropomorphic priming) is required to rule out alternative mechanisms (e.g., that forward-facing objects with motor capabilities prime status/power because they can collide with and injure the self).

More generally, these findings highlight a shortcoming of information processing models that have traditionally focused on verbal as opposed to visual stimuli even though print advertisements commonly contain both types of information (Wyer, Hung, \& Jiang, 2008). This focus on verbal information processing may miss how meaning shifts with visual representation. Although the influence of visual variables has long been recognized in the interpretive tradition of consumer research (for a discussion, see Allen, Fournier, $\&$ Miller, 2008), visual variables need more attention in information processing experiments as well.

\section{REFERENCES}

Aaker, J. L. (1997). Dimensions of brand personality. Journal of Marketing Research, 34, 347-356.

Aggarwal, P., \& McGill, A. L. (2007). Is that car smiling at me? Schema congruity as a basis for evaluating anthropomorphized products. Journal of Consumer Research, 34, $468-479$.

Allen, C. T., Fournier, S., \& Miller, F. (2008). Brands and their meaning makers. In C. P. Haugtvedt, P. Herr, \& F. R. Kardes (Eds.), Handbook of consumer psychology (pp. 781-822). New York: Psychology Press.

Barsalou, L. W. (2008). Grounded cognition. Annual Review of Psychology, 59, 617-645.

Belk, R. W. (1978). Assessing the effects of visible consumption on impression formation. Advances in Consumer Research, $5,39-47$.

Belk, R. W. (1988). Possession and the extended self. Journal of Consumer Research, 15, 139-168.

Chandler, J., \& Schwarz, N. (2010). Use does not wear ragged the fabric of friendship: Thinking of objects as alive makes people less willing to replace them. Journal of Consumer Psychology, 20, 138-145.

Chiao, J. Y., Adams, Jr., R. B., Tse, P. U., Lowenthal, W. T., Richeson, J. A., \& Ambady, N. (2008). Knowing who's boss: fMRI and ERP investigation of social dominance perception. Group Processes and Intergroup Relations, 11, 201-214.

Darley, W. K. (2010). Guest editorial: The interaction of online technology and the consumer shopping experience. Psychology \& Marketing, 27, 91-93. 
Dovidio, J. F., Ellyson, S. L., Keating, C. F., Heltman, K., \& Brown, C. E. (1988). The relationship of social power to visual displays of dominance between men and women. Journal of Personality and Social Psychology, 54, 233242.

Eagly, A. H., Wood, W., \& Diekman, A. (2000). Social role theory of sex differences and similarities: A current appraisal. In T. Eckes \& H. M. Trautner (Eds.), The developmental social psychology of gender (pp. 123-174). Mahwah, NJ: Erlbaum.

Epley, N., Waytz, A., \& Cacioppo, J. T. (2007). On seeing human: A three-factor theory of anthropomorphism. Psychological Review, 114, 864-886.

Fennis, B. M., \& Pruyn, A. T. H. (2007). You are what you wear: Brand personality influences on consumer impression formation. Journal of Business Research, 60, 634-639.

Giessner, S. R., \& Schubert, T. W. (2007). High in the hierarchy: How vertical location and judgments of leaders' power are interrelated. Organizational Behavior and Human Decision Processes, 104, 30-44.

Higgins, E. T., Rholes, W. S., \& Jones, C. R. (1977). Category accessibility and impression formation. Journal of Experimental Social Psychology, 13, 141-154.

Higgins, E. T. (1996). Knowledge activation: Accessibility, applicability, and salience. In E. T. Higgins \& A. W. Kruglanski (Eds.), Social psychology: Handbook of basic principles (pp. 133-168). New York: Guilford Press.

Hoegg, J., \& Alba, J. W. (2008). A role for aesthetics in consumer psychology. In C. P. Haugtvedt, P. Herr, \& F. R. Kardes (Eds.), Handbook of consumer psychology (pp. 733754). New York: Psychology Press.

Ichikawa, H., Kanazawa, S., \& Yamaguchi, M. K. (2011). Finding a face in a face-like object. Perception, 40, 500 502.

Kleine, R., Kleine, S., \& Kernan, J. (1993). Mundane consumption and the self: A social identity perspective. Journal of Consumer Psychology, 2, 209-235.

Kleinke, C. L. (1986). Gaze and eye contact: A research review. Psychological Bulletin, 100, 78-100.

Kraft, R. N. (1987). The influence of camera angle on comprehension and retention of pictorial events. Memory and Cognition, 15, 291-307.

Landwehr, J. R., McGill, A. L., \& Herrmann, A. (2011). It's got the look: The effect of friendly and aggressive "facial" expressions on product liking and sales. Journal of Marketing, 75, 132-146.

Meier, B. P., \& Dionne, S. (2009). Downright sexy: Verticality, implicit power, and perceived physical attractiveness. Social Cognition, 27, 883-892.

Meyers-Levy, J., \& Peracchio, L. A. (1992). Getting an angle in advertising: The effect of camera angle on product evaluations. Journal of Marketing Research, 29, 454-461.

Mignault, A., \& Chaudhuri, A. (2003). The many faces of a neutral face: Head tilt and perception of dominance and emotion. Journal of Nonverbal Behavior, 27, 111-132.
Oyserman, D. (2009). Identity-based motivation: Implications for action-readiness, procedural-readiness, and consumer behavior. Journal of Consumer Psychology, 19, 250-260.

Peracchio, L. A., \& Meyers-Levy, J. (1994). How ambiguous cropped objects in ad photos can affect product evaluations. Journal of Consumer Research, 21, 190-204.

Peracchio, L. A., \& Meyers-Levy, J. (2005). Using stylistic properties of ad pictures to communicate with consumers. Journal of Consumer Research, 32, 29-40.

Reber, R., Schwarz, N., \& Winkielman, P. (2004). Processing fluency and aesthetic pleasure: Is beauty in the perceiver's processing experience? Personality and Social Psychology Review, 8, 364-382.

Schembri, S., Merrilees, B., \& Kristiansen, S. (2010). Brand consumption and narrative of the self. Psychology \& Marketing, 27, 623-637.

Schubert, T. W. (2005). Your highness: Vertical positions as perceptual symbols of power. Journal of Personality and Social Psychology, 89, 1-21.

Schwarz, N. (2007). Attitude construction: Evaluation in context. Social Cognition, 25, 638-656.

Smith, E. R., \& Semin, G. R. (2004). Socially situated cognition: Cognition in its social context. In M. P. Zanna (Ed.), Advances in experimental social psychology (pp. 53-117). San Diego, CA: Elsevier Academic Press.

Srull, T. K., \& Wyer, R. S. (1979). The role of category accessibility in the interpretation of information about persons: Some determinants and implications. Journal of Personality and Social Psychology, 37, 1660-1672.

Vanderheiden, S. (2006). Assessing the case against the SUV. Environmental Politics, 15, 23-40.

Wedel, M., \& Pieters, R. (Eds.). (2007). Visual marketing: From attention to action. New York: Psychology Press.

Wilson, T. D., \& Brekke, N. (1994). Mental contamination and mental correction: Unwanted influences on judgments and evaluations. Psychological Bulletin, 116, 117-142.

Windhager, S. W., Slice, D. E., Schaefer, K., Oberzaucher, E., Thorstensen, T., \& Grammer, K. (2008). Face to face: The perception of automotive designs. Human Nature, 19, 331346.

Wyer, R. S. (2008). The role of knowledge accessibility in cognition and behavior: Implications for consumer information processing. In C. P. Haugtvedt, P. Herr, \& F. R. Kardes (Eds.), Handbook of consumer psychology (pp. 31-76). New York: Psychology Press.

Wyer, R. S., Hung, I. W., \& Jiang, Y. (2008). Visual and verbal processing strategies in comprehension and judgment. Journal of Consumer Psychology, 18, 244-257.

Yeh, W., \& Barsalou, L. W. (2006). The situated nature of concepts. American Journal of Psychology, 119, 349-384.

Correspondence regarding this article should be sent to: Jonathon P. Schuldt, Department of Communication, Cornell University, Ithaca, NY 14850 (jps56@cornell.edu). 